\title{
Aplicabilidade da metodologia de reação de polimerase em cadeia em tempo real na determinação do percentual de organismos geneticamente modificados em alimentos
}

\author{
Applicability of the real-time polymerase chain \\ reaction based-methods in quantification of \\ genetically modified organisms in foods
}

Natália Eudes Fagundes de BARROS ${ }^{1}$

Edna Maria Morais OLIVEIRA ${ }^{1}$

Victor Augustus MARIN²

\section{RE S U M O}

\begin{abstract}
A detecção de organismos geneticamente modificados na cadeia alimentar é um aspecto importante para todos os assuntos envolvidos no controle de matéria-prima, na indústria de alimentos e na distribuição. A rotulagem e a rastreabilidade de organismos geneticamente modificados são questões atuais que são consideradas para o comércio e a regulamentação. Atualmente, a rotulagem de alimentos processados contendo material transgênico detectável é exigida pela legislação brasileira. 0 governo brasileiro publicou Decreto no 4.680 em abril de 2003, que exige rotulagem para todos os alimentos ou ingredientes de alimento, com o limite para rotulagem de $1 \%$. Embora a tecnologia de reação em cadeia da polimerase tenha algumas limitações, a alta sensibilidade e especificidade explicam sua escolha por parte dos laboratórios interessados em realizar análises de detecção de organismos geneticamente modificados e seus derivados. Entre os métodos atualmente disponíveis, aqueles baseados na reação em cadeia da polimerase geralmente são aceitos, considerando a sensibilidade e a confiabilidade na detecção de material geneticamente modificado-derivado em análises de rotina. Neste artigo, apresenta-se uma revisão de métodos atualmente disponíveis baseados na reação em cadeia da polimerase para detecção, identificação e quantificação de organismos geneticamente modificados e seus derivados, discutindo sua aplicabilidade e suas limitações.
\end{abstract}

Termos de indexação: Alimentos geneticamente modificados. Reação de polimerase em cadeia. Rotulagem de alimentos.

\footnotetext{
${ }^{1}$ Embrapa Agroindústria de Alimentos. Av. das Américas, 29501, Guaratiba, 23020-470. Rio de Janeiro, RJ, Brasil. Correspondência para/Correspondence to: N.E.F. BARROS E-mail: «nataliaeudes@usp.br>.

2 Fundação O sval do Cruz, Instituto N acional de Controle de Qualidade e Saúde, Departamento Microbiologia. Rio de Janeiro, RJ, Brasil.
} 


\section{A B S T R A C T}

Detection of genetically modified organisms in the food chain is an important issue for all subjects involved in raw material control, food industry and distribution. Both labeling and traceability of genetically modified organisms are current issues that are considered for trade and regulation. Currently, labeling of genetically modified foods containing detectable transgenic material is required by the Brazilian legislation. The Brazilian government published the Decree $\mathrm{n} 04.680$ in April 2003, which requires labeling for all foods or food ingredients, with a stricter labeling threshold of $1 \%$. Although polymerase chain reaction technology has some limitations, the high sensitivity and specificity explain why it has been the first choice of most analytical laboratories interested in detection of genetically modified organisms and their derived products. Among the currently available methods, polymerase chain reaction-based methods are accepted, considering the sensitivity and reliability for detection of genetically modified-derived material in routine analysis. In this paper, a review of currently available polymerase chain reaction methods for screening and quantifying genetically modifiedderived ingredients is presented, discussing their applicability and limitations.

Indexing terms: Foods genetically modified. Polymerase chain reaction. Food labeling.

\section{N T R O D U Ç Ã O}

Organismos geneticamente modificados (OGMs) são aqueles que tiveram o seu material genético alterado pela introdução de um ou mais genes por meio de técnicas de biologia molecular. Esse processo é capaz de conferir às plantas novas características, tais como resistência a pesticidas, melhor tolerância ao estresse ambiental, ou modificar sua qualidade nutricional. A transgenia pode contribuir significativamente para o melhoramento genético de vegetais, visando a otimizar a produção de alimentos, fármacos, bem como outros produtos industriais ${ }^{1}$.

A área cultivada com plantas transgênicas avançou dos 1,7 milhão de hectares registrados em 1996 para cerca de 90 milhões de hectares em 2005. Atualmente, 21 países têm autorização para plantio e comercialização de plantas geneticamente modificadas $(G M)^{2}$. As culturas transgênicas autorizadas para comercialização são inúmeras, sendo as principais soja, milho, algodão e canola ${ }^{3}$. Nos Estados Unidos, mais de $50 \%$ do algodão, $45 \%$ da soja e $40 \%$ do milho cultivados passaram por alguma alteração genética, e pelo menos, $60 \%$ dos produtos industrializados contêm $\mathrm{OGM}^{4}$.

A circulação no mercado, ao longo dos anos, de alimentos derivados de OGM s indica que a segurança da saúde humana e do meio-ambiente podem ser avaliadas segundo os procedimentos disponíveis ${ }^{5}$. Apesar disso, a preocupação do público consumidor torna-se um obstáculo para a liberação no mercado de novos produtos alimentícios derivados de OGM, pois uma das maiores barreiras à aceitação dos alimentos geneticamente modificados (AGM) é a falta de informação do consumidor que, quando em dúvida, assume uma posição contrária ao seu consumo. É importante ressaltar que OGM é o produto agrícola (grãos, frutas, hortaliças etc.) que sofre a modificação genética; e que AGM pode ser um OGM ou um alimento preparado à base de um OGM .

Nesse contexto, o sistema que regula a liberação de AGM deve atender às necessidades de informação e segurança do consumidor. Assim, faz-se necessário que a avaliação quanto à segurança do produto geneticamente modificado preceda sua introdução no mercado consumidor. Além disso, seria adequado o desenvolvimento de um programa de vigilância após o lançamento de produtos derivados de OGM, para avaliar possíveis efeitos a longo prazo, decorrentes do consumo de tais produtos. Dessa forma, as agências reguladoras estariam garantindo ao consumidor o direito de escolha entre AGM e alimentos não geneticamente modificados, por meio do estabelecimento de procedimentos de separação, rastreabilidade, detecção e rotulagem ${ }^{6}$.

No Brasil, a aprovação para a comercialização do plantio de soja Roundup Ready 
(RR) - M onsanto, tolerante ao herbicida glifosato com fins comerciais é regulamentada pela Lei de Biossegurança, no 11.105, de 24/03/2005, sendo que os produtos contendo OGM s com níveis acima de $1 \%$ devem exibir no rótulo informações específicas ao consumidor (Figura 1), de acordo com 0 Decreto no 4.680 de 23/04/2003. Além da soja, recentemente a Comissão Técnica Nacional de Biossegurança (CTNBio) emitiu parecer favorável à comercialização de algodão geneticamente modificado, resistente a insetos, além da aprovação para importação de alguns eventos de milho destinados à ração animal7.

A legislação brasileira estabelece um percentual mínimo de OGM a partir do qual a rotulagem indicativa de transgenia se faz obrigatória, mas sem considerar os diferentes ingredientes do alimento em questão. Já na União Européia, a determinação prevista no Regulamento (CE) n- $1.829 / 2003$, de 22 de setembro de 2003 - relativo a gêneros alimentícios e alimentos para animais geneticamente modificados - e no Regulamento (CE) no 1.830/2003, de 22 de setembro de 2003 - relativo à rastreabilidade e rotulagem de organismos geneticamente modificados e à rastreabilidade dos gêneros alimentícios e alimentos para animais produzidos a partir de organismos geneticamente modificados ${ }^{8}$-, prevê rotulagem obrigatória em produtos que apresentam 0,9\% ou mais de OGM nos ingredientes individuais que

Quantificação OGMs

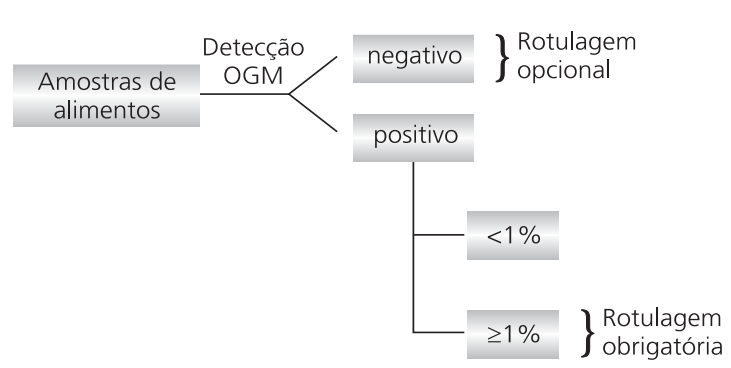

Figura 1. Procedimentos operacionais para detecção e quantificação de soja GM de acordo com a regulamentação de rotulagem no Brasil. entraram no seu preparo. Já nos Estados Unidos, no caso de o OGM apresentar equivalência substancial ao convencional, a indicação do rótulo não se faz necessária9?.

A introdução dos OGM s na cadeia alimentar gerou um intenso debate público e científico a respeito dos seus riscos e da necessidade de fornecer informações ao consumidor ${ }^{10}$. Assim, as técnicas de detecção de alimentos transgênicos vêm sendo aprimoradas, a fim de identificar gêneros produzidos à base de OGMs, ou eventuais contaminações na cadeia produtiva ${ }^{11}$. 0 progresso observado na amostragem, as metodologias de detecção e as estratégias de investigação influenciaram fortemente o potencial de implementação e manutenção da legislação especifica e da rotulagem ${ }^{12}$. A detecção e a quantificação de OGM s têm sido de grande importância no comércio internacional, especialmente em países que permitem tanto a rotulagem para a presença como para a ausência de transgênicos ${ }^{13}$.

Em virtude de a legislação exigir a rotulagem de alimentos apresentando OGM s acima de $1 \%$, faz-se necessária a adoção de metodologias que possibilitam a quantificação de transgênicos. Assim, a técnica mais adequada para este fim tem sido a Reação em Cadeia da DNA Polimerase (Polymerase Chain Reaction - PCR) em tempo real, que permite a determinação da concentração dos produtos de amplificação durante a fase exponencial do PCR, permitindo traçar uma estimativa da quantidade inicial do DNA (ácido desoxirribonucléico) amplificado ${ }^{4}$. Esta metodologia tem sido validada para detecção de OGMs em estudos anteriores ${ }^{14-19}$.

Greiner et al..$^{20}$ analisaram 100 produtos alimentícios à base de soja e outros 100 à base de milho, comercializados no Brasil em 2000 e 2001, através da PCR quantitativa em tempo real. Desses, $13 \%$ dos produtos à base de soja, em 2000, e 21\%, em 2001, apresentavam a soja RR, dentre os quais farinha de soja, produtos à base de tofu, sopas instantâneas, isolado protéico de soja, alimentos para dietas vegetarianas e produ- 
tos de panificação. Nos produtos à base de milho, foi detectada a presença de Bt176, Bt11 (Novartis) e/ou MON810 (Monsanto) em $8 \%$ e $9 \%$ dos alimentos nos anos de 2000 e 2001, respectivamente, em amostras de biscoitos, polenta e farinha de milho. Cardarelli et al. ${ }^{21}$ analisaram 89 alimentos à base de soja e/ou milho, e destes, 16 produtos (18\%) apresentaram soja tolerante a glifosato, sendo que nenhum alimento apresentou milho GM. Brod et al. ${ }^{22}$ analisaram 37 produtos alimentares à base de soja, e destes, 19 produtos (51\%) apresentaram resultado positivo para a presença de soja RR.

\section{Reação em cadeia da DNA polimerase}

A tecnologia da PCR é baseada nos princípios da replicação do DNA fita dupla, o mecanismo responsável pela transmissão da informação genética nas células.

Trechos de DNA genômico podem ser amplificados in vitro sob condições específicas, nas quais são adicionados ao meio reacional oligonucleotídeos curtos - primers ou iniciadores (apresentando seqüência de bases complementar ao DNA molde), DNA polimerase termoestável e deoxinucleotídeos. Ciclos dessa reação produzem fragmentos de DNA de seqüências especificas, mesmo a partir de traços de DNA molde (em 3 horas, obtém-se, aproximadamente, $10^{9}$ cópias) (Figura 2) ${ }^{23}$. O DNA pode ser isolado a partir de inúmeras amostras, inclusive alimentos, utilizando-se técnicas apropriadas para cada material.

A técnica de PCR apresenta alto grau de seletividade e sensibilidade, critérios estes que fazem com que este método seja o mais empregado na maioria dos laboratórios analíticos interessados na detecção de OGM se seus subprodutos. Tendo em vista o fato de que os produtos destinados a análise geralmente já sofreram algum tipo de processamento que pode interferir na integridade e quantidade do analito alvo (Ex. proteína ou DNA), é necessário considerar possíveis interferências na sensibilidade, qualquer que seja 0

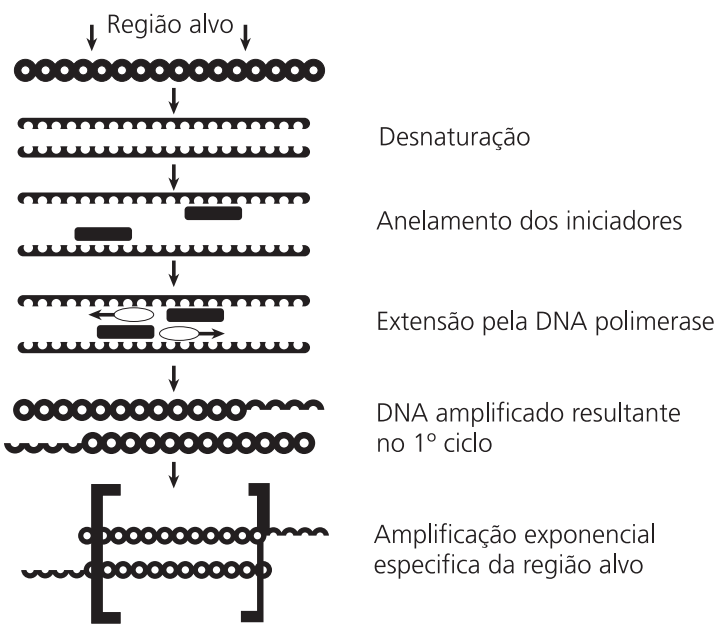

Figura 2. Representação esquemática do princípio da técnica de PCR (Adaptada de Meyer ${ }^{21}$ ).

método a ser utilizado ${ }^{24,25}$. Dentre os métodos disponíveis, aqueles baseados na técnica de PCR em geral são aceitos como os mais sensíveis e fidedignos para detecção de materiais derivados de OGM s em análises de rotina ${ }^{26}$.

Por ser a PCR uma técnica amplamente utilizada, a principal limitação na detecção de OGM sé a dificuldade em ter acesso a informações sobre seqüências de oligonucleotídeos aplicáveis à PCR e seqüências de DNA apropriadas às análises, para que estas últimas possam fornecer resultados seguros. Embora nos últimos 10 anos várias seqüências de oligonucleotídeos tenham sido desenvolvidas e publicadas, muitas dessas são aplicáveis somente à identificação específica dos principais OGM s disponíveis comercialmente. Para a maioria dos OGMs liberados para plantio e comercialização não existem pares de oligonucleotídeos aplicáveis à quantificação ${ }^{27}$. Além disso, até o presente momento, foram desenvolvidos pelo Institute of Reference Materials and M easurements (Geel, Bélgica) somente oito materiais de referência certificados ${ }^{28}$, o que dificulta o desenvolvimento e a validação dos métodos analíticos.

Outra limitação é a degradação do DNA provocada por etapas do processamento dos alimentos, tais como tratamentos físicos, químicos 
e enzimáticos. Como conseqüência, muitos produtos contêm traços de DNA derivado de OGM, sendo este, em sua maioria, altamente degradado ${ }^{24}$. Na soja Roundup Ready, processos tais como trituração, cocção, coagulação, homogeneização e desidratação resultam em degradação do DNA, sendo que fragmentos de DNA endógeno (gene lectina) se mostram mais estáveis do que genes exógenos (gene CP4-EPSPS), fatores estes que podem exercer influência sobre a análise de detecção e identificação/quantificação de OGM s²9. Essa situação exige que a estratégia experimental permita a garantia da especificidade da análise por PCR, utilizando diferentes pares de primers que amplificam regiões distintas do gene-alvo (Figura 3).

Os principais fatores que podem exercer influência sobre os critérios de performance na detecção de OGM s são as etapas de amostragem, sub-amostragem, e extração de DNA ${ }^{30}$. A purificação de DNA a partir das amostras de alimentos é crítica na preparação das amostras para o $\mathrm{PCR}^{31}$. Em geral, o DNA isolado a partir de alimentos processados é altamente degradado, e precisa ser separado e isolado de lipídeos, proteínas, polissacarídeos e sais, pois estes poderiam exercer efeito inibitório sobre a DNA polimerase $^{23,25}$.

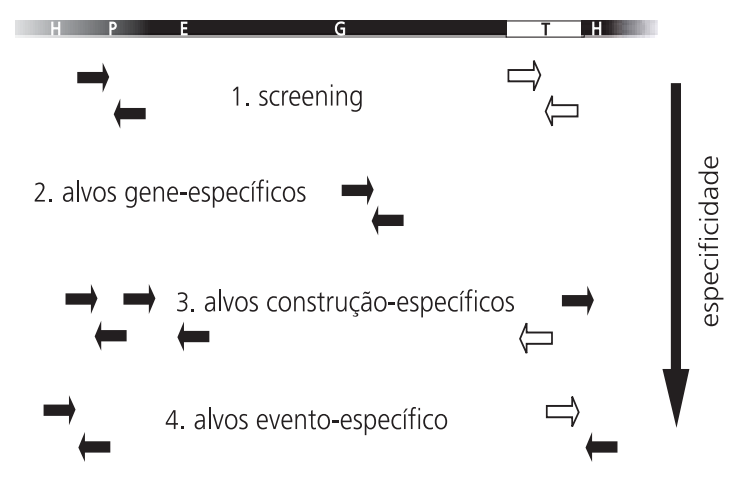

Figura 3. Representação esquemática do grau de especificidade da detecção de OGM s segundo o PCR realizado; $\mathrm{H}$ : DNA genômico da planta receptora; P: promotor; E: elemento enhancer; $\mathrm{G}$ : gene de interesse; $\mathrm{T}$ : terminador; gene inserido representado por $\mathrm{P}+\mathrm{E}+\mathrm{G}+\mathrm{T}$ (adaptado de Holst-Jensen et al. ${ }^{25}$ ).

\section{Análise quantitativa}

Para atender à legislação de rotulagem, 0 teor de OGM deve ser determinado. Quando há necessidade de análise quantitativa, esta deve ser conduzida em relação a um parâmetro definido. Na legislação européia, é estabelecida como relativa ao ingrediente (ex.: farinha de milho), comumente interpretada peso/peso, mas em princípio deveria se relacionar a uma quantidade específica (volume ou peso) da matriz, por número de unidades (partículas, moléculas de DNA ou proteínas). Entretanto, não existe uma relação exata entre peso ou número de grãos e moléculas de DNA. Geralmente considera-se que a melhor estimativa é obtida com técnicas que determinam o número de moléculas de DNA obtido a partir de uma unidade de peso/grão. Berdal \& Holst-Jensen ${ }^{32}$ desenvolveram um produto apresentando $10 \%$ ( $p / p$-peso/peso) ver nota de soja transgênica, utilizando uma matriz bem caracterizada, mas análises baseadas na detecção de DNA revelaram percentual de, aproximadamente, $12 \%$. Estes resultados poderiam ser atribuídos a diferentes teores de DNA por unidade de peso da matriz (OGM relativo a soja não GM).

\section{PCR em tempo real}

O PCR em tempo real permite o monitoramento da reação de amplificação em tempo real (ciclo a ciclo), em sistema fechado, sem interferências externas no progresso da reação ${ }^{32}$. Um sinal fluorescente é detectado em proporção ao aumento da quantidade do produto de amplificação. Essa fluorescência é emitida por compostos fluoróforos, que podem estar ligados a sondas (Taqman) ou intercalados na dupla fita do DNA amplificado (SYBR Green). As sondas são seqüências de DNA que se ligam à região central da seqüência-alvo, aumentando a seletividade do método. A pesar das vantagens da técnica de PCR em tempo real, esta ainda apresenta custo elevado e requer treinamento especializado ${ }^{33}$.

No computador que está acoplado ao termociclador no qual ocorre a PCR, cada reação 
de amplificação é mostrada como uma linha colorida (Figura 4). A fluorescência emitida em resposta à síntese do produto de amplificação é detectada em tempo real. 0 aumento desse produto nos ciclos iniciais é pouco significativo. Com o progresso da reação, pode se observar um aumento do sinal emitido (fase exponencial). Quando esse aumento da fluorescência passa a ser estatisticamente significante, atinge-se o nível threshold (linha horizontal), o ciclo da reação de PCR correspondente é chamado ciclo threshold $(\mathrm{Ct})^{32}$. A quantificação pode ser realizada por comparação direta dos valores de fluorescência detectada no Ct (método $\Delta \mathrm{Ct}$ ), ou por comparação do número de cópias utilizando-se uma curva padrão (método de curva padrão). Para uma amostra desconhecida, duas reações com a mesma concentração de DNA molde podem ser realizadas, uma delas tendo como região alvo para amplificação um gene endógeno de referência (Endog), e a outra reação um trecho da construção relativa à modificação genética (alvo). As duas reações representando essa amostra desconhecida são mostradas no gráfico como linhas pretas. A diferença de $\mathrm{Ct}(\Delta \mathrm{Ct})$ para os dois alvos ( $\mathrm{Ct}$ alvo - Ct Endóg) pode ser utilizada diretamente para estimar o percentual de OGM, segundo a seguinte fórmula:

$$
\frac{1}{2^{\Delta \mathrm{Ct}}} \times 100 \%=\% \text { OGM }
$$

Já no método de curva padrão, é realizada uma série de reações nas quais o número de cópias de cada alvo é conhecido. Uma curva de regressão relaciona o número de cópias do alvo produzidas na reação de amplificação ao ct, permitindo a estimativa do número inicial de cópias do fragmento alvo. 0 percentual de OGM na amostra pode ser estimado pela comparação entre o número de cópias do alvo detectadas no $\mathrm{Ct}$, pela seguinte fórmula:

$$
\mathrm{N}_{\text {alvo }} / \mathrm{N}_{\text {Endóg }} \times 100=\% \text { OGM }
$$

No exemplo mostrado no gráfico (Figura 4), $\Delta \mathrm{Ct}=30,0$ (Ct alvo) - 23,3 (Ct endog)=6,7, correspondendo a, aproximadamente, 1\% OGM

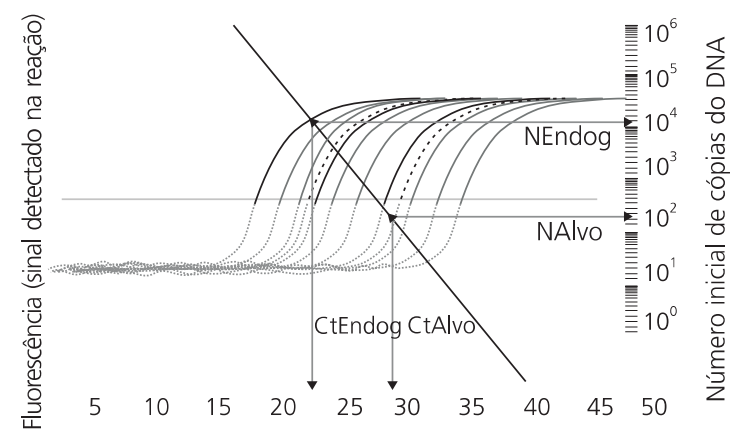

Figura 4. Amplificação em PCR quantitativo em tempo real (adaptado de Holst-Jensen et al. ${ }^{25}$ ).

(pelo método $\Delta \mathrm{Ct}$ ). 0 mesmo resultado é observado quando utilizado o método de curva padrão, já que $\mathrm{N}_{\text {alvo }}=10^{2}$ e $\mathrm{N}_{\text {Endóg }}=10^{4} 25$. Isto é, em um produto no qual a soja não seja ingrediente único, a quantificação se dá tendo como base o percentual de soja GM em relação à soja convencional, e não em relação à totalidade dos ingredientes. Por exemplo, uma sopa desidratada, que tenha como ingrediente o isolado protéico de soja, apresentando $2 \%$ de soja GM, significa que, de cada $10 \mathrm{~g}$ de isolado protéico, $0,2 \mathrm{~g}$ tem origem transgênica.

A quantificação de OGM s geralmente tem como seqüência alvo, na reação de PCR em tempo real, o promotor $35 \mathrm{~S}$, um elemento regulador obtido do vírus do M osaico da Couve-flor (CaMV) $)^{34}$. Esse tipo de análise deve ser desenvolvido de modo a excluir o risco de resultados falso-positivos. Isso se deve ao fato de que alguns vegetais, como Brassicaceae e Solanaceae, são hospedeiros naturais do CaM V. Recentemente, pesquisadores desenvolveram um sistema de quantificação que utiliza sondas M GB (M inor Groove Binder) para amplificar especificamente o CaMV em amostras de alimentos. Assim, para que as análises implementadas para detecção/quantificação usando como gene-alvo 035 S não apresentem falso-positivo, também devem ser conduzidas reações para a amplificação do CaMV. Dessa forma, a quantidade de vírus contaminante poderá ser estimada $^{14}$. 
O impacto econômico da introdução dos OGMs na cadeia alimentar evidencia a importância das determinações de ausência/presença desses produtos em alimentos. Essas análises devem ser realizadas utilizando metodologias aprovadas e validadas. A validação e a harmonização de métodos quantitativos é absolutamente necessária para 0 atendimento às legislações para a rotulagem de produtos que apresentem em sua composição, um percentual de OGM superior ao limite permitido; além da certificação de produtos agrícolas destinados à exportação que devam conter informações sobre possível contaminação porOGMs.

No Brasil, existe um esforço conjunto do Ministério da Agricultura e do M inistério da Saúde, por intermédio da Agência Nacional de Vigilância Sanitária (ANVISA), para o estabelecimento de uma rede de laboratórios credenciados para a condução das análises de detecção/quantificação dos OGM s que circulam no mercado.

Esta estratégia alcançará maior importância quando a nova geração de OGM s, com alterações na qualidade nutricional e as chamadas biofábricas, chegarem ao mercado consumidor. Além disso, o desenvolvimento de sistemas de detecção/quantificação de OGMs cada vez mais seletivos e sensíveis facilitará a rastreabilidade desses organismos, em um programa de vigilância pós-mercado. É importante ressaltar ainda que com um programa de vigilância pós-mercado delineado, pode-se garantir, a longo prazo, a segurança de alimentos produzidos a partir de OGMs. Essas informações serão importantes para 0 consumidor, que poderá optar, sem receio, pelo consumo de alimentos contendo OGM s.

\section{O LA BORADORES}

N.E.F. BARROS, E.M.M. OLIVEIRA e V.A. MARIN contribuíram substancialmente para a concepção, planejamento do trabalho e na redação do artigo.

\section{REFER Ê N C IA S}

1. Nodari RO, Guerra MP. Plantas transgênicas e seus produtos: impactos, riscos e segurança alimentar. Rev Nutr. 2003; 16(1):105-16.

2. James, C. Executive summary of global status of commercialized biotech/GM Crops: 2005. ISAAA Briefs No. 34. ISAAA [cited $2005 \mathrm{Mar}$ 14]. A vailable from: <http://www.isaaa.org/kc/bin/briefs34/es/ index.htm>.

3. Cavalli SB. Segurança alimentar: a abordagem dos alimentos transgênicos. Rev Nutr. 2001; 14(Supl): 41-6.

4. Ahmed FE. Detection of genetically modified organisms in foods. Trends in Biotechnol. 2002; 20(5):215-23.

5. National Research Council. Genetically modified pest-protected plants: science and regulation [cited 2002 Nov 2]. Available from: <http://nationalacademies.org $>$.

6. Schilter B, Constable A. Regulatory control of genetically modified (GM) foods: likely developments. Toxicol Letters. 2002; 127(1-3): 341-9.

7. Brasil. Comissão Técnica Nacional de Biossegurança. Commercial Aprovals [cited 2007 May 9]. Available from: <http://www.ctnbio.gov.br/ index.php/content/view/3662.html>.

8. União Européia. Rastreabilidade e rotulagem dos organismos geneticamente modificados (OGM) [cited 2006 Apr 6]. A vailable from: <http://europa. eu.int/scadplus/leg/pt/lvb/l21170.htm>.

9. Van Den Eede G, Kay S, Anklam E. Analytical challenges: brindging the gap from regulation to enforcement. J AOAC Int. 2002; 85(3):757-61.

10. Gracia Arnaiz M. Piensando sobre el riesgo alimentario y su aceptabilidad: el caso de los alimentos transgénicos. Rev Nutr. 2004; 17(2): 125-49.

11. Germini A, Zanetti A, Salati C, Rossi S, Forré C, Schmid S, et al. Development of a seven-target multiplex PCR for the simultaneous detection of transgenic soybean and maize in feeds and foods. J Agric Food Chem. 2004; 52(11):3275-80.

12. Miraglia M, Berdal KG, Brera C, Corbisier C, Holst-Jensen A, KOK A, et al. Detection and traceability of genetically modified organisms in the food production chain. Food Chem Toxicol. 2004; 42(7): 1157-80.

13. Tozzini $A C$, Martinez MC, Lucca MF, Rovere $C V$, Distéfano AJ, Del Vas $M$, et al. Semi-quantitative detection of genetically modified grains based on CaMV $35 S$ promoter amplification. Electronic J Biotech. 2000; 3(2):1-5. 
14. Cankar K, Ravnikar M, ZEL J, Gruden K, Toplar N. Real-time pollymerase chain reaction detection of Cauliflower mosaic virus to complement the $35 \mathrm{~S}$ screeening assay for genetically modified organisms. J AOAC Int. 2005; 88(3):814-22.

15. Corbisier P, Trapmann S, Ganeberg D, Hannes L, Van Iwaarden P, Berben G, et al. Quantitative determination of roundup ready soybean (glycine max) extracted from highly processed flour. Anal Bioanal Chem. 2005; 383(2):282-90.

16. Feinberg M, Fernandez S, Cassard S, Charles-Delobel C. Quantification of the 35S promoter in maize DNA extracts from genetically modified organisms using real-time polymerase chain reaction: Part 2: interlaboratory study. J AOAC Int. 2005; 88(2):558-73.

17. Fernandez S, Charles-Delobel C, Geldreich A, Berthier G, Boyer F, Collonnier C, et al. Quantification of the 35S promoter in DNA extracts from genetically modified organisms using realtime pollymerase chain reaction and specificity assessment on various genetically modified organisms: Part 1: Operating procedure. J AOAC Int. 2005; 88(2):547-57.

18. Taverniers I, Van Bockstaele E, De Loose M. Cloned plasmid DNA fragments as calibrators for controlling GMOs: different real-time duplex quantitative PCR methods. Anal Bioanal Chem. 2004; 378(5):1198-207.

19. Weighardt F, Barbati C, Paoletti C, Querci M , Kay S, De Beuckeleer $M$, et al. Real-time PCR based approach for quantification of the pat gene in the T25 Zea Mays event. J AOAC Int. 2004; 87(6): 1342-55.

20. Greiner $\mathrm{R}$, Konietzny $U$, Villavicencio $A L C H$. Qualitative and quantitative detection of genetically modified maize and soy in processed foods sold commercially in Brazil by PCR-based methods. Food Control. 2005; 16(8):753-9.

21. Cardarelli P, Branquinho M R, Ferreira RTB, Cruz FP, Gemal AL. Detection of GMO in food products in Brazil: the INCQS experience. Food Control. 2005; 16(10): 859-66.

22. Brod FCA, Ferrari CS, Valente LL, A risi ACM . Nested PCR detection of genetically modified soybean in soybean flour, infant formula and soymilk. LWT 2007; 40: 748-51.

23. Meyer R. Development and application of DNA analytical methods for the detection of GMOs in food. Food Control. 1999; 10(6):391-9.
24. Peano C, Samson M C, Palmieri L, Gulli M, Marmiroli N. Qualitative and quantitativeevaluation of the genomic DNA extracted from GMO and Non-GM O foodstuffs with four different extraction methods. J Agric Food Chem. 2004; 52(23):6962-8.

25. Terry CF, Harris N, Parkes HC. Detection of GM crops and their derivatives: critical steps in sample preparation and extraction. J AOAC Int. 2002; 85(3):768-74.

26. Giovannini T, Concilio L. PCR Detection of genetically modified organisms: a review. Starch. 2002; 54(8):321-7.

27. Holst-Jensen A, De Loose M, Van Den EEDE. Coherence between Legal requirements and approaches for detection of genetically modified organisms (GMOs) and their derived products. J Agric Food Chem. 2006; 54(8):2799-809.

28. Institute of Reference Materials and M easurements reference materials catalogue [cited 2006 Feb 3]. Available from: <http://www.irmm.jrc. be/>.

29. Chen $Y$, Wang $Y, G e Y, X u$ B. Degradation of endogenous and exogenous genes of Roundup Ready Soybean during food processing. J Agric Food Chem. 2005; 53(26):10239-43.

30. Bertheau Y, Diolez A, Kobilinsky A, Magin K. Detection methods and performance criteria for genetically modified organisms. J AOAC Int. 2002; 85(3): 801-8.

31. Deisingh A, Badrie N. Detection approaches for genetically modified organisms in foods. Food Res Int. 2005; 38(6):639-49.

32. Berdal KG, Holst-Jensen A. Roundup ready soybean event-specific real-time quantitative PCR assay and estimation of the practical detection and quantification limits in GMO analyses. Eur Food Res Technol. 2001; 213(6):432-8.

33. Wiseman G. State of the art and limitations of quantitative polymerase chain reaction. J AOAC Int. 2002; 85(3):792-6.

34. Fernandez S, Charles-Delobel C, Geldreich A, Berthier G, Boyer F, Collonnier C, et al. Quantification of the 35S promoter in DNA extracts from genetically modified organisms using real-time polymerase chain reaction and specificity assessment on various genetically modified organisms, part l: operating procedure. I AOAC Int. 2005; 88(2):547-57.

Recebido em: 12/5/2006

Versão final reapresentada em: 25/5/2007 Aprovado em: 22/10/2007 